\title{
Depressive Symptoms in Patients with Obstructive Sleep Apnea
}

\author{
Harun Karamanlı1, Fatih Kayhan², Recep Akgedik ${ }^{3}$ \\ 'Department of Pulmonology, Atatürk Chest Diseases and Chest Surgery Training and Research Hospital, Ankara, Turkey \\ ${ }^{2}$ Department of Psychiatry, Selcuk University Faculty of Medicine, Konya, Turkey \\ ${ }^{3}$ Department of Pulmonology, Ordu University Faculty of Medicine, Ordu, Turkey
}

Abstract OBJECTIVES: Different studies have investigate depressive symptom degree within sleep disordered patients with obstructive sleep apnea (OSA). However, little is known and unclear about OSA in patients with depression symptom in the literature. The purpose of this study was to investigate patients with OSA would have a higher prevalence of depression symptom relative to control patients.

MATERIAL AND METHODS: 72 patients with OSA (AHI $\geq 5$ ) and 24 control subjects (AHI < 5) were assessed for depression symptom using the Beck Depression Inventory. Participants were underwent an overnight polysomnography assessment. An apnea-hypopnea index $\geq 5$ events per hour was used as diagnosis for OSA. The associations between each total score on the Beck Depressive Inventory (BDI) and polysomnographic parameters were examined by correlation analysis.

RESULTS: We demonstrated that BDI scores has statistically significant correlation with the OSA in our present study according to similar previous studies $(p=0.008)$. Oxygen Desaturation Index $(\mathrm{ODI})$ has correlated with BDI $(r=0.31)$.

CONCLUSION: These findings show that the frequency depression symptom is higher among individuals with OSA. Patients with OSA should be screened cautiously for depressive disorders.

KEYWORDS: Obstructive sleep apnea, depressive symptoms, beck depression index

Received: 10.07.2015

Accepted: 25.11 .2015

\section{INTRODUCTION}

Obstructive sleep apnea (OSA) is a common form of sleep-disordered breathing defined by repetitive upper airway obstruction during sleep and concurrent hypoxemia, causing excessive daytime sleepiness (EDS) and sleep fragmentation. Apart from EDS, other symptoms may also compromise quality of life, cause neuropsychological changes, affect day time activities, trigger cognitive dysfunction, and lead to psychological changes, including depression [1-3]. Depressive symptoms overlap those of many medical conditions, including OSA [4,5]. Again, OSA is common and adversely affects psychological well-being. Consequently, OSA symptoms may simulate those of depressive conditions.

Moreover, overlapping symptoms, such as a reduction in or loss of facial expression, deficitsin task initiation, and slower (passive) psychomotor functioning, may develop in those with either depression or OSA (reflecting diurnal sleepiness in the latter patients). Some patients may have intermediate conditions [6]. Although the association between OSA and depression remains unclear, OSA is associated with the presence of depressive symptoms. Clinically, the disturbed sleep of depressed individuals is abnormal in structure and cannot halt the progression of depressive symptoms.

Assessment of depressive symptoms is a substantial task. Several scales have been developedand confirmed as measures of the severity of depressive symptoms; these include the popular Beck Depressive Inventory (BDI), which is moderately specific and sensitive when used toidentify depressive disorders in both otherwise healthy individuals and those with comorbid medical conditions [7,8]. OSA patients have scored higher than controls on the BDI [9].

The existence of a relationship between depression and OSA remains speculative. Some authors have suggested that sleep fragmentation and the oxygen desaturation associated with OSA trigger depression [10,11]. However, others found no relationship between depressive symptoms and OSA [12]. However, it is reasonable to state that OSA is associated with the presence of depressive symptoms.

The aim of the present study was to measure the frequency of depressive symptoms in OSA patients, to describe these symptoms, and to determine patient characteristics according to the severity of OSA. In addition, we examined which

Address for Correspondence: Harun Karamanlı, Atatürk Göğüs Hastalıkları ve Göğüs Cerrahisi Eğitim ve Araştırma Hastanesi, Ankara, Türkiye Phone: +90 (312) 5677000 E-mail: drharun@hotmail.com 
OSA variables (the apnea-hypopnea index [AHI], the arousal index, the minimal oxygen saturation level, and/or the oxygen desaturation index) most accurately predicted the presence of depressive symptoms?

\section{MATERIAL AND METHODS}

\section{Clinical Characteristics of Patients}

We managed this research at the sleep laboratory of Mevlana University, from Jun 2014 to January 2015. All patients who provided the standard indications for polysomnographic evaluation for the suspected diagnosis of OSA were appropriate for registration into the research. Incomplete and unhealthy events were removed from the research; for this reason, the knowledge were collected from 96 patients who were evaluated to diagnose for OSA in respect of ICSD-3. Before information collection, informed consent was obtained from each participant. The information about gender, age, height, weight, and medical history of the patients was obtained and analyzed, and unnecessary information were eliminated.

Criteria for inclusion in the research were: A clinical history of severely snoring and witnessed apnea, No patients had chronic lung disease, and none were receiving bronchodilator treatment. No other psychiatric disorders, including personality disorders or substance dependence, anxiety disorder, no serious medical disorders, such as cerebral vascular disease, cardiac disease, neurological disease or; renal dysfunction, no other sleep disorders, such as periodic limb movements or hypersomnia.

Patients were interviewed and evaluate dusing three tools.

1. The ESS (Epworth Sleepiness Scale) questions the personal to rate the subjective sleepiness in eight different particular conditions, on a 0-3 scale, with 0 meaning no possibility at all of falling asleep, and 3 showing a high possibility of falling asleep. Hence, outcoming in a final score of 0 (least sleepy) to 24 (most sleepy). There is a fixed scoring recommendation of 10 as a probably excessive daytime sleepiness.

\section{Depressive Symptoms}

The Beck Depression index is a 21-item questionnaire used to assess self-reported depressive symptoms [13]. Though the $\mathrm{BDI}$ is not enough to diagnose depressive disorders, the BDI has been commonly utilized on to assess depressive symptoms and has been established to be sensitive and moderately specific in describing depressive disorders, both in otherwise healthy personals and in patients with comorbid medical diseases [14]. The Beck scores categorized the severity depression into four groups in successive attitude. BDI categories are normal (0-9), mild (10-15), moderate (16$23)$, and severe (24-63).

\section{Polysomnography}

Afterwards, whole individuals get through two nights of standard polysomnography System (Philips Respironics, Murrayville, PA) with Alice Sleepware Software. This polysomnogram is for diagnosing OSA containing four electroencephalograms (C3-A2, C4-A1, O1-A2, O2- A1) right and left electroculograms and electromyograms of anterior tibialis muscles and chin, oral and nasal flow with a thermistor, abdominal and thoracic respiratory movements with a tightness measure, and arterial oxygen saturation with a finger oximeter.

Sleep stages were scored in $30 \mathrm{~s}$ epochs in respect of the criteria and respiratory incidents were scored using standard criteria by a physician blind to the purpose of the research and the subject's identity. Apnea was described as a total interruption of airflow continues at least $10 \mathrm{~s}$. Hypopnea was described as $50 \%$ or greater decrease in airflow continues at least $10 \mathrm{~s}$ and related with arousal from sleep [15]. The apnea-hypopnea index (AHI) was described as the score of apneas + hypopneas per hour of sleep. Apnea severity indices contained $\mathrm{AHI}$ and mean arterial oxygen saturation.

In the current research, the $\mathrm{AHI}$ criteria for OSA were based upon the ICSD-3, requiring an $\mathrm{AHI} \geq 5$ as a cutoff number for OSA. Hence, the sample was separated into two groups: those with an $\mathrm{AHI} \geq 5$, referred to as the OSA group, and those with an $\mathrm{AHI}<5$, referred to as the control group [16].

To assess obesity, we determined the BMI, which is figured out as body weight in kilograms divided by the square of the height in meters. Obesity was defined by a body mass index $30 \mathrm{~kg} / \mathrm{m}^{2}$ figured out from self-reported weight and height. The Mevlana University Medical Faculty ethics committee approved the study and patients who agreed to participate in the research gave informed consent.

\section{Statistical Analysis}

Means with standard deviations or percentages were used to describe the sample. OSA group and control group differences were evaluated with unpaired t-tests. Comparison forcategorical variables was done using the chi-square test or Fisher's exact test, where appropriate was used to compare these proportions in different groups. We analyzed the correlations among improvement rates in BDI scores, $\mathrm{AHI}$, ODI, mean arterial oxygen saturation, and alterations in various sleep structures using the Pearson correlation. A p value $<0.05$ was took into consideration statistically significant. Data analyses were conducted using Statistical SPSS 15 (California states, US).

\section{RESULTS}

The baseline characteristics of patients and normal control subjects are shown in Table 1 . The mean total BDI score ( \pm SD) was $13.5 \pm 9.1$, and females did not score significantly higher than males $(10.5 \pm 8.7)(p=0.09)$ in this regard. The OSA group had a mean BDI score of $12.9 \pm 9.8$, and the control grouphad a mean score of $8.8 \pm 4.7(p=0.008)$ (Table 1).

Patient distribution by BDI category is shown in Table 2. More than half of all OSA patients (59.7\%) had depressive symptoms; about $34.7 \%$ had scores suggesting at least mild depression, and about $25 \%$ had scores suggesting moderateto-severe depression. 
Table 1. The baseline characteristics of the patients and normal control subjects are shown in Table 1

\begin{tabular}{|c|c|c|c|}
\hline Characteristics & GRUP I $(A H I$ > 5) & GRUP II $(A H I<5)$ & $p$ value \\
\hline Participants & 72 & 24 & \\
\hline Male/female & $42 / 30$ & $10 / 14$ & 0.36 \\
\hline Age, yr. & $51.4 \pm 13$ & $45.6 \pm 11.1$ & 0.14 \\
\hline BMI & $33.8 \pm 6.5$ & $30.8 \pm 6.4$ & 0.2 \\
\hline ESS score & $9.0 \pm 6.8$ & $8.0 \pm 5.3$ & 0.43 \\
\hline AHI, per $h$ & $31.8 \pm 22.7$ & $1.8 \pm 1.5$ & $<0.0001$ \\
\hline Mean $\mathrm{SaO}_{2}, \%$ & $92.6 \pm 2.6$ & $94.5 \pm 1.5$ & $<0.0001$ \\
\hline Lowest $\mathrm{SaO}_{2}, \%$ & $76.2 \pm 11.8$ & $88.8 \pm 2.3$ & $<0.0001$ \\
\hline ODI & $37.0 \pm 27.9$ & $4.3 \pm 5.1$ & $<0.0001$ \\
\hline Arousal index & $19.5 \pm 13.2$ & $9.8 \pm 4.4$ & $<0.0001$ \\
\hline BDI & $12.9 \pm 9.8$ & $8.8 \pm 4.7$ & 0.008 \\
\hline
\end{tabular}

Table 2. Information about prevalence distribution of patients according to the BDI categories

\begin{tabular}{|c|c|c|c|}
\hline BDI groups & OSA (+) & Control & $p$ value \\
\hline Normal & $29(\% 40.3)$ & $11(\% 45.8)$ & \\
\hline Mild depression symptom score & $25(\% 34.7)$ & $11(\% 45.8)$ & \\
\hline Moderate depression symptom score & $9(\% 12.5)$ & $2(\% 8.3)$ & \\
\hline Severe depression symptom score & $9(\% 12.5)$ & none & \\
\hline Total & $72(\% 100)$ & $24(\% 100)$ & 0.509 \\
\hline
\end{tabular}

Correlations were found between higher BDI scores and ODI $(r=0.31, p=0.002)$. Other OSA severity variable $(\mathrm{AHI}, \mathrm{Al}$, mean $\mathrm{SaO}_{2}$, Lowest $\mathrm{SaO}_{2}$ ) was not correlated with BDI scores (Table 3).

We were compared categorical variables. Neither the BMI northe gender distribution differed between the OSA and control groups. Thus, between-group sex differences were evaluated and any statistical difference was not obtained ( $p>0.05)$. ESS (Epworth sleepiness scale) not influence BDI scores.

\section{DISCUSSION}

We sought to identify the depressive symptoms associated with OSA and the correlations between various parameters of sleep apnea and depression. We found that the presence of depressive symptoms increased the risk of OSA, which is in agreement with earlier findings indicating that OSA was closely linked to depression. According to the BDI, 41 $(59.7 \%)$ and 29 (40.3\%) of OSA patients exhibited or lacked depressive symptoms, respectively. The control group included $11(45.8 \%)$ asymptomatic subjects. More than half the OSA patients $(59.7 \%)$ reported depressive symptoms. A previous study found that the overall prevalence of such symptoms among those with sleep disorders was high, as $41 \%$ of OSA patients had significant levels of depression, and a meta-analysis showed that $7-63 \%$ of OSA patients were depressed $[17,18]$. The wide range is attributable to variations among populations.

Females exhibited a some what higher frequency of depressive symptoms, although this difference did not reach statistical significance. The frequencies of depressive symptoms were independent of the analytical tool employed.

We also used the oxygen desaturation index (ODI) to determine if ODI values were correlated with BDI scores. It is possible that severe oxygen desaturation during sleep plays a significant role in the development of neuropsychological disturbances, increasing BDI scores. The ODI clearly affected

Table 3. Pearson correlation scroe between BDI and OSA severity index parameters

\begin{tabular}{|c|c|c|c|c|c|c|c|}
\hline Variables & BMI & $\mathrm{AHI}$ & Mean $\mathrm{SaO}_{2}$ & ODI & Lowest $\mathrm{SaO}_{2}$ & Arousal Index & ESS \\
\hline BDI & 0.13 & 0.24 & -0.20 & $0.31^{*}$ & -0.20 & 0.15 & 0.02 \\
\hline$p$ value & 0.20 & 0.019 & 0.048 & 0.002 & 0.06 & 0.12 & 0.85 \\
\hline
\end{tabular}


the frequency of depressive symptoms, as we found that ODI values were positively associated with BDI scores, supporting the hypothesis that OSA and depression may be associated. Nocturnal hypoxemia is associated with periodic reductions in oxygen saturation caused by disturbed respiration [19]. A strong correlation was evident between BDI scores and the ODI (which is a measureof OSA severity), which is consistent with the study conducted by Deldin et al., who explored whether individuals with depression had ventilatory and/or hypoxic abnormalities [20]. In contrast to controls, depressive individuals had more flow limitations/h, an increased proportion of such limitations associated with desaturation, and more desaturation events. The effect of OSA on the severity of depression was not explored [20]. In the context of hypoxemia, Engleman et al. showed that the extent of cognitive impairment in OSA patients was closely associated with the intensity of hypoxia [21]. Thus, the hypoxemia associated with OSA may also influence mood.

We found thatthe extent of respiratory distress (the AHI score) did not correlate with the BDI score. Likewise, the large study conducted by Pillar and Lavie with 2.271 clinical referrals (with RDI (respiratory desaturation index) scores $<10$ to $>$ 30) found no relationship in males between depressive symptoms and RDI scores obtained using the Symptom Checklist 90 [22]. The Hospital Anxiety and DepressionDepression Scale (HAD-D) scores of 44 Swiss OSA patients and 16 snorers were not correlated with their AHI scores [23]. However, most studies on OSA patients have found positive relationships between $\mathrm{AHI}$ scores and the severity of depressive symptoms. Andrews et al. considered that factors other than hypopnea and apnea, shared by depressive and OSA patients, explained the connection between OSA and depressive symptoms evident in many clinical studies [24]. Such variations infindings may be attributable to the use of different methodologies, especially the tools employed to identify depressive symptoms. Additionally, cut off scores varied and different factors were assessed. The development of depressive symptoms is complex and multifactorial. Further research is needed to determine the relationship between depressive symptoms and $\mathrm{AHI}$ scores.

The principal feature of OSA that may trigger sleep fragmentation is recurrent arousal associated with hypopnea and apnea. Sleep fragmentation explains the EDS of OSA patients. The EDS evaluated using the ESS was correlated with the extent of depression on the HAD-Din 44 patients with OSA [23]. However, wefound no correlation between the arousal index and BDI scores, probably because we measured depression differently.

In adults, OSA and depression have been shown to be related. We found no correlation between BDI scores and age or sex; $65.9 \%$ of female and $78.8 \%$ of male OAS patients had depressive symptoms. This is in contrast with the finding of a previous study in which the prevalence of depressive symptoms was greater in females [25].

We examined associations between BMI and the severity of sleep apnea. Subjects classified as "overweight" or "obese" were more prone to OSA compared with those who were "underweight" or within the "normal" weight range. As shown in several previous studies, wefound that high AHI scores (reflecting anincreasing severity of OSA) were associated with high BMIs $(p=0.028)$ [24]. However, we found no relationship between $\mathrm{BMI}$ and depressive symptoms.

Several limitations of our research should be mentioned. First, the number of subjects was limited. The cross-sectional design rendersthe interpretation of associations questionable. Patients were recruited from those who visited the sleep laboratory, which compromises the generalizability of our findings. The control group also had some OSA symptoms and were thus not representative of the general population. This may have caused us to underestimate the association between OSA and depressive symptoms. The numbers of females and males in the two groups differed. In addition, data were gathered using self-report questionnaires, and some subjects may thus have overstated their perceived problems.

However, systematic evaluation of depressive symptoms in OSA patientsusing standardized clinical questionnaires is routine in many sleep disorder laboratories. However, the questionnaires were not designed to evaluate depression in OSA patients in particular and may be inappropriate foruse in such patients, as it remains uncertain whether OSA and depression are true comorbidities or if they simply share symptoms $[24,26]$. For example, $31 \%$ of patients who snored only during the night had some form of depression. Consequently, some of our OSA patients complained chiefly of symptoms other than sleepiness and snoring, such as depression.

In conclusion, our results contribute to the emerging literature on the association between depressive symptoms and OSA and are thus of clinical significance. Depression was widespread in patients with OSA. Systematic assessment of depressive symptoms in OSA patients using clinical questionnaires is routine in sleep disorder centers. Collectively, the evidence suggests that individuals with depressive symptoms should be screened for OSA.

\section{Disclosure}

The authors have no conflicts of interest to declare in relation to this work.

The English in this document has been checked by at least two professional editors, both native speakers of English. For a certificate, please see: http://www.textcheck.com/ certificate/30At7d

Author Contributions: Concept - H.K.; - Supervision - H.K.; Analysis and/or Interpretation - F.K.; Litarature Review - H.K.; Writer - H.K.; Critical Review - R.A.

Conflict of Interest: No conflict of interest was declared by the author.

Financial Disclosure: The authors declared that this study has received no financial support. 


\section{REFERENCES}

1. Yang EH, Hla KM, McHorney CA, Havighurst T, Badr MS, Weber S. Sleep apnea and quality of life. Sleep 2000;23:535-41. [CrossRef]

2. O'Hara R, Schroder CM, Kraemer HC, et al. Nocturnal sleep apnea/hypopnea is associated with lower memory performance in APOE epsilon4 carriers. Neurology 2005;65:642-4. [CrossRef]

3. O'Hara R, Schroder C. Unraveling the relationship of obstructive sleep-disordered breathing to major depressive disorder. Sleep Med 2006;7:101-3. [CrossRef]

4. Carpenter KM, Hasin DS, Allison DB, Faith MS. Relationships between obesity and DSM-IV major depressive disorder, suicide ideation, and suicide attempts: results from a general population study. Am J Public Health 2000;90:251-7. [CrossRef]

5. Akashiba T, Kawahara S, Akahoshi T, et al. Relationship between quality of life and mood or depression in patients with severe obstructive sleep apnea syndrome. Chest 2002;122:861-5. [CrossRef]

6. Guilleminault C, Eldridge FL, Tilkian A, Simmons FB, Dement WC. Sleep apnea syndrome due to upper airway obstruction: a review of 25 cases. Arch Intern Med 1977;137:296-300. [CrossRef]

7. Gorenstein C, Andrade L. Validation of a Portuguese version of the Beck Depression Inventory and the State-Trait Anxiety Inventory in Brazilian subjects. Braz J Med Biol Res 1996;29:453-7.

8. Lustman PJ, Clouse RE, Griffith LS, Carney RM, Freedland KE. Screening for depression in diabetes using the Beck Depression Inventory. Psychosom Med 1997;59:24-31. [CrossRef]

9. Lee W, Lee SA, Chung YS, Kim WS. The relation between apnea and depressive symptoms in men with severe obstructive sleep apnea: mediational effects of sleep quality. Lung 2015;193:261-7. [CrossRef]

10. Adrien J. Neurobiological bases for the relation between sleep and depression. Sleep Med Rev 2002;6:341-51. [CrossRef]

11. Schroder CM, O'Hara R. Depression and Obstructive Sleep Apnea (OSA). Ann Gen Psychiatry 2005;4:13. [CrossRef]

12. McCall WV, Harding D, O'Donovan C. Correlates of depressive symptoms in patients with obstructive sleep apnea. J Clin Sleep Med 2006;2:424-6.

13. Beck AT, Ward $\mathrm{CH}$, Mendelson M, Mock J, Erbaugh J. An inventory for measuring depression. Arch Gen Psychiatry 1961;4:561-71. [CrossRef]
14. Carney RM, Rich MW, Tevelde A, Saini J, Clark K, Jaffe AS. Major depressive disorder in coronary artery disease. Am J Cardiol 1987;60:1273-5. [CrossRef]

15. Redline S, Budhiraja R, Kapur V, et al. The scoring of respiratory events in sleep: reliability and validity. J Clin Sleep Med 2007;3:169-200.

16. Berry RB, Budhiraja R, Gottlieb DJ, et al. Rules for scoring respiratory events in sleep: update of the 2007 AASM Manual for the Scoring of Sleep and Associated Events. Deliberations of the Sleep Apnea Definitions Task Force of the American Academy of Sleep Medicine. J Clin Sleep Med 2012;8:597-619.

17. Vandeputte $\mathbf{M}$, de Weerd $A$. Sleep disorders and depressive feelings: a global survey with the Beck depression scale. Sleep Med 2003;4:343-5. [CrossRef]

18. Saunamaki T, Jehkonen M. Depression and anxiety in obstructive sleep apnea syndrome: a review. Acta Neurol Scand 2007;116:277-

\section{8. [CrossRef]}

19. Cohen-Zion M, Stepnowsky C, Marler, et al. Changes in cognitive function associated with sleep disordered breathing in older people. J Am Geriatr Soc 2001;49:1622-7. [CrossRef]

20. Deldin PJ, Phillips LK, Thomas RJ. A preliminary study of sleepdisordered breathing in major depressive disorder. Sleep Med 2006;7:131-9. [CrossRef]

21. Engleman HM, Kingshott RN, Martin SE, Douglas NJ. Cognitive function in the sleep apnea/hypopnea syndrome (SAHS). Sleep 2000;23(Suppl 4):S102-S8.

22. Pillar G, Lavie P. Psychiatric symptoms in sleep apnea syndrome: effects of gender and respiratory disturbance index. Chest 1998;114:697-703. [CrossRef]

23. Sforza E, de Saint Hilaire Z, Pelissolo A, Rochat T, Ibanez V. Personality, anxiety and mood traits in patients with sleeprelated breathing disorders: effect of reduced daytime alertness. Sleep Med 2002;3:139-45. [CrossRef]

24. Andrews JG, Oei TP. The roles of depression and anxiety in the understanding and treatment of Obstructive Sleep Apnea Syndrome. Clin Psychol Rev 2004;24:1031-49. [CrossRef]

25. Sharafkhaneh A, Giray N, Richardson P, Young T, Hirshkowitz M. Association of psychiatric disorders and sleep apnea in a large cohort. Sleep 2005;28:1405-11. [CrossRef]

26. Baran AS, Richert AC. Obstructive sleep apnea and depression. CNS Spectr 2003;8:128-34. [CrossRef] 